Tropical Journal of Pharmaceutical Research, December 2006; 5 (2): 619-625

(C) Pharmacotherapy Group, Faculty of Pharmacy, University of Benin, Benin City, Nigeria. All rights reserved.

Research Article

Available online at http://www.tjpr.org

\title{
Assessment of the Knowledge of Community Pharmacists Regarding Common Phytopharmaceuticals Sold in South Western Nigeria
}

\author{
Rasaq Adisa ${ }^{1}$ and Titilayo Fakeye ${ }^{2 *}$ \\ ${ }^{1}$ State Ministry of Health, Osun State, NIGERIA \\ ${ }^{2}$ Department of Clinical Pharmacy \& Pharmacy Administration, University of Ibadan, Ibadan. NIGERIA.
}

\begin{abstract}
Purpose: The study was carried out to assess the knowledge of community pharmacists who sell herbal/phytopharmaceutical formulations in pharmacy retail outlets.

Method: Questionnaires were administered to the pharmacists to gather information on phytopharmaceuticals regarding their use, side effects, potential drug-herb interactions and contraindications of the phytopharmaceuticals sold in their retail outlets. Opinions on regulation, safety and efficacy of herbal remedies were also obtained. Descriptive statistical tests and median scores were used to evaluate the distribution of responses, opinions and perception of the pharmacists on their level of knowledge of the phytopharmaceuticals, and effects of demographic data on the pharmacists knowledge of the herbal remedies.

Results: The study revealed that 31 (62\%) sold imported herbal remedies and nutritional supplements. Seventy-two (72) \% had received no postgraduate training on herbal medications. Most of the community pharmacists agreed that they did not possess adequate knowledge of potential interaction profiles and side effects of the herbal remedies sold. The training in pharmacy schools on herbal drugs and sale of phytopharmaceuticals in their outlets also had no influence $(p>0.05)$ on desired knowledge. Community pharmacists with less than 10 years of experience in the practice however possessed better knowledge than pharmacists with more than ten years of professional practice $(p=0.05)$

Conclusions: There was gross inadequacy in the pharmacists' knowledge of the phytopharmaceuticals sold in pharmacies indicating an urgent need for intensive training in order to render better services to their clients.
\end{abstract}

Keywords: Community Pharmacists, Herbal formulations/Phytopharmaceuticals, Knowledge base, Pharmacology

*Corresponding Author: E-mail: titifakeye@yahoo.com; to.fakeye@mail.ui.edu.ng 


\section{INTRODUCTION}

A wide range of products such as herbal preparations, homeopathic remedies, and nutritional supplement of natural origin constitutes complementary medicine. Herbal products contain aerial or underground parts of plants or other plant materials or combinations of these. These could be in a crude state or as plant preparations, which may include juices, gums, fatty acids, essential oils and many other substances of nature for medicinal purposes ${ }^{1}$ and are also referred to as phytopharmaceuticals. Most patients usually think of herbal drugs as a risk-free option, and as a "safe and natural" alternative to conventional orthodox drugs ${ }^{2,3}$. Health professionals generally face the problem of assessing the effectiveness and safety of natural remedies. Information regarding these products is not readily available in official references. Some of these products have not been as extensively studied as allopathic drugs and are usually sold without much knowledge of their mechanisms of action or side effects ?

Though the use of complementary medicines is sometimes beneficial and the evidence for the efficacy of some of these medicines in literature is limited, they are often sold alongside allopathic drugs in pharmacies ${ }^{4}$. The sale and use of phytopharmaceuticals in combination with allopathic medicines are on the increase and have also found major use in self medication. The role of the community pharmacists in the use of complementary medicines cannot be undermined since these medicines are sold over-the-counter in pharmacies in some countries and as prescription medicines in others. Furthermore, patients generally depend on pharmacists for advice and information on drugs, including herbal remedies. In most developing countries, however, there is a serious lack of regulation of herbal medications beyond their safety. This is unlike what obtains in some developed countries ${ }^{5}$ which also seek to ensure that some of the claims of efficacy on the labels are met.

Imported

herbal

remedies/phytopharmaceuticals, which are widely sold in pharmacies in Nigeria, are not made to undergo rigorous efficacy screening, except for safety. Sometimes, few locally made herbal formulations are also sold in registered pharmacies. In a study carried out in the USA, there was observed a deficiency in knowledge base of pharmacists on the pharmacology of phytopharmaceuticals ${ }^{2}$. Literature is scanty on studies carried out on the level of knowledge of pharmacology possessed by pharmacists in the area of herbal formulations in developing countries, especially Nigeria, where lately there has been a trend to sell imported packaged herbal medicines alongside allopathic medicines. Therefore, there is a need to assess the level of knowledge of the community pharmacists who are, in developing countries, the custodians of these medications.

This study was carried out to assess the level of competence and knowledge of community pharmacists in southwestern Nigeria on the use, safety profile, drug interaction potential and effectiveness of herbal remedies sold in pharmacies. The pharmacists' opinions about regulatory issues, professional responsibilities in the sale and use of herbal formulations, and level of training required for competence were also investigated.

\section{METHODS}

The list of Association of Community Pharmacists of Nigeria (ACPN) in the states available as at time of study was used as the source for selection of pharmacists in the study. Informed consent of the pharmacists taking part in the study was obtained. From the available records of 250 licensed premises in the year 2004 in the two states as at the time of the study, seventy registered community pharmacists in the region were selected with one Pharmacist being chosen per premises. Every third pharmacy on the list was chosen. The inclusion criteria included a registered pharmacy with a superintendent pharmacist in attendance at least 8 hours daily. In cases where a pharmacy has branches or other outlets, only one of its outlets was selected. Pharmacies in rural areas were excluded.

Study design and data collection:Questionnaire, which was the instrument used for collecting information, was designed to 
obtain demographic data such as year of qualification, year of practice as a community pharmacist; elicit relevant information on their level of awareness, attitude and relevant training received on the use of herbal drugs, legal and ethical values, and their perceived professional responsibilities towards complementary medicines especially herbal drugs. In this study, we tried to differentiate herbs from vitamins and minerals. A herbal drug was defined as a refined or raw extract from plant origin excluding multivitamins or minerals. This however includes multivitamin or mineral preparations containing ingredients such as Gingko biloba or ginseng of any origin. A survey of herbal remedies sold in those pharmacies was collected from the pharmacies. The most common ten of these were chosen for the study. The knowledge base of the community pharmacists on the uses, contraindications and potential drug-herb interactions was tested by the use of fifteen (15) questions which were based on common interactions of these herbs. Each question had one correct answer, two incorrect answers and a "no idea" response. The questionnaires were given to the selected community pharmacists to be filled in their respective pharmacies. The name of the pharmacy or pharmacist was not requested for on the questionnaire to ensure anonymity of the respondents. The pharmacists were informed that their response would help in determining whether there is adequate training or there is need for additional training for pharmacists in the area of herbal remedies.

The questionnaires were pre-tested among five experienced leading community pharmacists in the locality who were not included in the study.

Data Analysis: The correct answers to the questions were obtained using peer-reviewed journal articles on the subjects ${ }^{6-11}$. Responses to questions on pharmacology of specific herbs were graded. Each correct answer was assigned a score of "1" while a non-response, a wrong answer or a "no idea" response was scored "0". The maximum obtainable score was 15 and the pass mark was set at 8 out of $15(53 \%)$.

Descriptive statistics was used for the responses of the community pharmacists. Comparison of the median scores obtained by respondents was used to evaluate if the difference observed in scores was due to influence of certain variables on the knowledge base of the pharmacists on the pharmacology of herbal medicine. Statistical significance was set at $p \leq 0.05$.

\section{RESULTS}

A total of 70 questionnaires were given out to the respondents but only $50(71.4 \%)$ were properly filled and analyzed. Table 1 shows the summary of the respondent's scores based on certain variables.

Majority of the respondents, 37 (74\%), scored less than $53 \%$ (i.e. below 8 out of 15) on the questions on the use, adverse effects and interaction potentials of the commonly sold herbal formulations/ nutritional supplements in their area. Only $1(2 \%)$ scored above $70 \%$ while $5(10 \%)$ and $7(14 \%)$ scored $53-59 \%$ and 60 $69 \%$ respectively. It was observed that only 14 respondents $(28 \%)$ had earlier received a form of training on complementary medicines usually in form of workshop and seminars while 36 respondents $(72 \%)$ had not received any. Fortytwo $(84 \%)$ pharmacists had less than 10 years of experience in community pharmacy practice while only 8 respondents $(16 \%)$ had put more than 10 years of practice into community pharmacy. Respondents with less than ten years post graduation experience showed better knowledge $(p \leq 0.05)$ than their counterparts with over 10 years experience (Table 1 ).

It was observed that 31 respondents (62\%) stock herbal and nutritional supplements in their outlets while 19 respondents (38\%) claimed not to because they possess little knowledge about these medicines and may not be able to provide the needed information on these medications to their clients.

A majority, $39(78 \%)$, were of the opinion that pharmacists are the most qualified professional to handle the sale and supply of complementary medicines while $7(14 \%)$ chose patent medicine shops and the remaining 4 (8\%); different combinations of herb shops or road-side hawkers for sale of complementary medicines. The most common mode of sale of complementary medicines was through demand by patients (20 respondents; $40 \%$ ) while 9 pharmacists $(18 \%)$ sell based on the complaints 
Table 1: Scores obtained by different groups of respondents

\begin{tabular}{|c|c|c|c|c|c|}
\hline $\begin{array}{c}\text { Basis of } \\
\text { Classification } \\
\end{array}$ & $\begin{array}{c}\text { Group of } \\
\text { respondents }\end{array}$ & $\begin{array}{c}\text { Frequency (\% } \\
\text { frequency) }\end{array}$ & Mean score \pm SD & Median & P value \\
\hline \multirow[t]{2}{*}{ Training } & $\begin{array}{c}\text { Postgraduation } \\
\text { training } \\
\text { (workshops, } \\
\text { seminars etc) }\end{array}$ & $14(28)$ & $6.43 \pm 2.44$ & 6.50 & \multirow[t]{2}{*}{0.13} \\
\hline & $\begin{array}{l}\text { Without } \\
\text { postgraduation } \\
\text { training }\end{array}$ & $36(72)$ & $5.36 \pm 2.18$ & 5.00 & \\
\hline \multirow{2}{*}{$\begin{array}{l}\text { Carrying of } \\
\text { complementary } \\
\text { medicines }\end{array}$} & Yes & $31(62)$ & $5.94 \pm 2.41$ & 5.00 & \multirow[t]{2}{*}{0.40} \\
\hline & No & $19(38)$ & $5.37 \pm 0.65$ & 5.00 & \\
\hline \multirow{2}{*}{$\begin{array}{l}\text { Postgraduation } \\
\text { experience }\end{array}$} & $>10$ years & $8(16)$ & $4.25 \pm 1.67$ & 5.00 & \multirow[t]{2}{*}{0.13} \\
\hline & $\leq 10$ years & $42(84)$ & $6.00 \pm 2.35$ & 6.00 & \\
\hline \multirow{2}{*}{$\begin{array}{l}\text { Relationship with } \\
\text { traditional } \\
\text { medical doctor }\end{array}$} & Yes & $23(46)$ & $5.48 \pm 2.35$ & 5.00 & \multirow[t]{2}{*}{0.42} \\
\hline & No & $27(54)$ & $5.93 \pm 2.34$ & 6.00 & \\
\hline \multirow{2}{*}{$\begin{array}{l}\text { Who should } \\
\text { stock } \\
\text { complementary } \\
\text { medicines }\end{array}$} & Pharmacists & $39(81)$ & $5.62 \pm 2.72$ & 5.00 & \multirow{2}{*}{0.47} \\
\hline & $\begin{array}{l}\text { Traditional } \\
\text { Medical } \\
\text { Practitioners }\end{array}$ & $9(19)$ & $6.00 \pm 1.41$ & 6.00 & \\
\hline \multirow[t]{2}{*}{$\begin{array}{l}\text { Years of practice } \\
\text { as community } \\
\text { pharmacist }\end{array}$} & $\leq 10$ years & $42(84)$ & $6.00 \pm 2.35$ & 5.50 & \multirow[t]{2}{*}{$0.05^{\star}$} \\
\hline & $>10$ years & $8(16)$ & $4.25 \pm 1.67$ & 4.00 & \\
\hline
\end{tabular}

$$
\text { * - significant at } \mathrm{p}=0.05
$$

given by the patients. Only 2 (4\%) sold based on prescription or recommendation by medical doctors. On the question of what group of complementary medicines should be sold only by pharmacists, $16(32 \%)$, responded that both herbal remedies and nutritional supplements should be sold only by pharmacists.

A large number of respondents, 39 (78\%) were of the opinion that the National Agency for Food \& Drug Administration \& Control (NAFDAC) should also be charged with the responsibility for regulating the sales and supply of complementary medicines in the country as it is being presently done for allopathic medicines. Five $(10 \%)$ were however of the opinion that the regulation on complementary medicines should be the responsibility of the Pharmacists Council of Nigeria (PCN) while one respondent $(2 \%)$ believed that the Traditional Medical Council should be responsible for the regulation of the sale and supply of these medicines. Some respondents, $36(72 \%)$ agreed that the code of ethics of pharmacy profession is in support of 
Table 2: Opinion of community pharmacists to the effectiveness and safety of herbal medications

\begin{tabular}{ll}
\hline Opinion (Safety) & Frequency \\
\hline Highly safe & 28 \\
Moderately safe & 34 \\
Mildly safe & 18 \\
Not Safe & 8 \\
Opinion (Effectiveness) & 18 \\
Highly effective & 44 \\
Moderately effective & 22 \\
Mildly effective & 4 \\
Not effective & \\
\hline
\end{tabular}

community pharmacists handling the sale and supply of complementary medicines.

The majority, 47 (94\%), cited basic pharmacognosy courses done during undergraduate pharmacy training in the university as the only formal training they had received in herbal remedies. They also suggested the incorporation of complementary medicine training into the undergraduate Pharmacy curriculum. Many $(43,86 \%)$ believed that pharmacists should acquire adequate and formal training on complementary medicines as this would enhance their professional skill and knowledge of complementary medicines. However, 7 (14\%) believed that constant reading of available up-to-date literature and not necessarily formal training is required. Some 24 $(48 \%)$ believed that herbal medicines and nutritional supplements should be classified as over-the-counter (OTC) medicines, 17 (34\%) as prescription-only-medicines (PoM) while 9 (18\%) were of the opinion that they should be classified as dietary supplements.

It was observed that respondents had different opinions on the safety and efficacy of these medicines as shown in Table 2 . Only $13(26 \%)$ claimed to have observed gastrointestinal disturbances such as diarrhea as the only form of adverse reactions in some patients using complementary medicines.

\section{DISCUSSION}

The pharmacists involved in this study were selected from the list of registered pharmacists in two of the states located in southwestern part of Nigeria. However, the list contained the names of pharmacists who had completed their registration as at September, 2004 only. There exists the possibility that the list was not representative of the pharmacists in the region since finance is one of the factors which may cause late registration. Also, there might have been more knowledgeable pharmacists (in the area of complementary medicines) in the other five geo-political zones of the country, though this is not likely since the region studied has four of the approved pharmacy schools in the country.

Though a majority of the pharmacists claimed that the only training they had received on herbal drugs was the basic pharmacognosy course, pharmacists with less than 10 years post graduation experience scored higher than their counterparts who had graduated earlier. This may either be due to more relevant topics on the subject which were introduced while they were under training, or that this group of pharmacists, being younger and more recent graduates, had kept up to date by reading scientific publications that had to do with herbal remedies. This question was however not raised during the course of the study. The undergraduate training in pharmacognosy received by the majority of respondents included topics on unorganized and organized vegetable drugs, separation techniques, and drugs of biological origin. Knowledge of medicinal plants and traditional medicine was perceived by the respondents to be elementary compared to the needed knowledge especially in the area of 
pharmacology of herbal medications. A similar study carried out in $2000^{2}$ in some cities of United States of America showed that continuing education in herbal remedies placed pharmacists at an advantage in their knowledge base. Majority of the respondents recognized their inadequacies with phytopharmaceuticals and observed a need for incorporating training on the pharmacology of phytopharmaceuticals into the undergraduate pharmacy curriculum.

The Pharmacists Council of Nigeria (PCN) and the National Universities Commission (NUC), which are the bodies responsible for the training of pharmacists in Nigeria, have in recent time called for review and upgrading of courses taught in pharmacy to reflect the recent trends in pharmacy programme worldwide, and this includes pharmacognosy and pharmacology courses as well. Previous studies ${ }^{4,12}$ have shown that though undertaking training does not necessarily reflect adequate knowledge or competence, the content, relevance, quality and duration of training are also important.

Although herbal medicines are not sold by some respondents due to their limited knowledge, majority of the respondents believed that pharmacists are the most qualified professional to handle the sale and supply of complementary medicines and therefore should take up the challenge of re-education in the use and potential interaction profile of complementary medicines generally and herbal remedies specifically. This response was similar to those observed by Chang et $\mathrm{al}^{2}$ and were in line with the submission of Barnes ${ }^{4}$ where it was emphasized that the issue of complementary medicines is an area that pharmacists cannot afford to ignore and it is obvious that community pharmacists need to develop their knowledge base on herbal remedies in order to be able to advise patients appropriately ${ }^{2,13}$.

Most of the pharmacists rightly believed there is need for a more intensive effort on the part of NAFDAC to ensure the safety and efficacy of herbal drugs. Safety issues are not sufficient for herbal drugs. The efficacy of the herbal drugs imported into the country should also be ensured by making sure that they are accompanied by a certificate that proper pharmacological and quality control have been carried out on these groups of drugs and that honest claims about the efficacy are being made (as they are being presently being done for allopathic drugs). The ones that are formulated and advertised for public use locally should also undergo tests that will establish or refute the efficacy claims. Another problem that may be causing the seeming inaction of NAFDAC regarding herbal drugs may be due to the fact that in Nigeria, as in a number of countries, some botanical products are sold as food or food supplements, meaning that no claims on the efficacy of the products can be made. In practice, this means that there are a large number of botanical products which are freely available in the country. In some other countries however, these preparations are seen as medicine with full or simplified registration requirements. In a number of countries, these products are automatically linked to a pharmacyonly status ${ }^{14-19}$. These differences indicate that there may be no consensus on the classification of botanical products, since basically two different approaches are followed namely: botanical health products under food legislation, and herbal medicinal products under pharmaceutical legislation. Though countries such as Brazil have been able to put up rules that will ensure the efficacy and safety issues of some of their herbal drugs, ineffectiveness of Governmental Inspection Agencies is however a problem in such places ${ }^{20}$.

This study revealed a gross deficiency in the knowledge base of community pharmacists on pharmacology of herbal remedies especially since it is this group of pharmacists that have more contact with members of their communities either for advice / consultation on drugs. Future plan will involve the evaluation of the pre- and post impact of an intervention programme on the knowledge base of community and hospital pharmacists on pharmacology and relevant questions on phytopharmaceuticals.

\section{CONCLUSION}

This study revealed that most community pharmacists interviewed generally had poor knowledge of the common phytopharmaceuticals sold in their pharmacies. There is a need for community pharmacists to 
constantly educate themselves in order to be properly equipped to face the challenge of providing optimal care and counseling for patients who use herbal remedies. Pharmacists also need to get more familiar with the safety, drug interaction potentials and efficacy of herbal remedies sold in their pharmacies.

\section{References}

1. WHO. General guidelines for methodologies in research and evaluation of traditional medicine. World Health Organisation, Geneva WHO/EDM/TRM/2000 (1) pp1-80

2. Chang ZG, Kennedy DT, Holdford DA, Small RE. Pharmacists' knowledge and attitudes toward herbal medicines. The Annals of Pharmacotherapy. 2000; 34(6): 710-715

3. Anthony S. It's natural so it must be safe. Australian Prescriber, 2002; 25(3): 50-51.

4. Barnes J. Complementary medicines and Pharmacist The Pharmaceutical Journal 1999; 263(7067): 644- 646

5. Aalt Bast, R. Frank Chandler, Patrick C. Choy, Luc M. Delmulle, Joerg Gruenwald, S. Bart A. Halkes et al., Botanical health products, positioning and requirements for effective and safe use. Environmental Toxicology and Pharmacology 2002; 12:195-211

6. Janetzky K, Morreale AP. Probable interaction between warfarin and ginseng. American Journal of Health System Pharmacist 1997; 54: 692-693

7. Matthews MK Jr. Association of Ginkgo biloba with intracerebral hemorrhage. Neurology 1998; 50:1933

8. Johne A, Brockmöller J, Bauer S, Maurer A, Langhein- rich $\mathrm{M}$, Roots I. Pharmacokinetic interaction of digoxin with an herbal extract from St. John wort (Hypericum perforatum) Clinical Pharmacology \& Therapeutics 1999; 66: 338-345

9. Ko Richard. Adverse reactions to watch for in patients using herbal remedies. Western Journal of Medicine, 1999; 171(3): 181-186.

10. Fugh-Berman A, Ernst E. Herb-drug interaction: review and assessment of report reliability. British Journal of Clinical Pharmacology 2001; 52:587595

11. Izzo AA, Ernst E. Interactions between herbal medicines and prescribed drugs: a systematic review. Drugs 2001; 61: 2163-2175

12. Barnes J, Anderson LA, Phillipson JD Herbal Medicines A Guide for Health Care Professionals. Second Edition, London, Pharmaceutical Press. 2000

13. Barnes J. Pharmacovigilance of Herbal medicine: a UK perspective. Drug Safety, 2003; 26(12): 829-851

14. Benzi G \& Ceci A. Herbal medicines in European regulations Pharmacology Research 1997; 35: 355-362

15. WHO. Regulatory situation of herbal medicines. World Health Organisation, Geneva 1998; pp1-25

16. EAS Marketing food supplements, fortified and functional food in Europe. European Advisory Services, Brussels. 2000

17. Mansaray M. Herbal remedies - food or medicines? Chemistry \& Industry 2000; 677-678

18. AESGP. Herbal medicinal products in the European Union. The Association of the European SelfMedication Industry, Brussels. 1998; pp1-45

19. Scneider E. Herbs as functional food: regulation-safetyquality assurance. Deutsche Lebensm Rundsch 2001; 97: 300-305

20. Petrovick PR, Marques LC, De Paula IC. New rules for phytopharmaceutical drug registration in Brazil. Journal of Ethnopharmacology 1999; 66: 51-55 